\title{
Uma crítica às facetas da medicalização pela gestão dos riscos
}

\author{
Flávia Cristina Silveira Lemos, (iD I, ${ }^{\star}$ Maria Lívia do Nascimento, ${ }^{(D)}{ }^{I I}$ Dolores Galindo (D) III \\ ${ }^{I}$ Universidade Federal do Pará, Belém, PA, Brasil \\ ${ }^{\text {II }}$ Universidade Federal Fluminense, Niterói, RJ, Brasil \\ III Universidade Federal de Mato Grosso, Cuiabá, MT, Brasil
}

\begin{abstract}
Resumo
Este artigo realiza uma análise teórica em formato de problematização de acontecimentos atuais, entre eles, em especial, a medicalização pela gestão dos riscos, na educação, na cidade, no trabalho e na família. Para tanto, apresenta subsídios conceituais, baseados na filosofia, psicologia, educação, sociologia e história. Práticas da Organização Mundial da Saúde sobre a classificação dos corpos e as políticas decorrentes são parte da engrenagem de medicalização da educação e da sociedade, no presente, por meio da gestão dos riscos. Uma certa maneira de governar a vida e as condutas é fundada pela regulação medicalizante dos corpos, na atualidade. Assim, objetiva-se contribuir para a discussão dessa prática e dos seus efeitos preocupantes, nas experiências de ser. É possivel concluir que a medicalização se amplia na lógica da formação da subjetividade saudável e de um suposto estilo de existência pautado na noção de bem-estar e qualidade de vida como aspectos comportamentais e ligados à percepção de riscos. Desse modo, a medicalização passa a operar pela promoção da saúde como gestão de riscos em nome da saúde como performance educativa e preventiva.
\end{abstract}

Palavras-chave: medicalização; educação; governo da vida; gestão dos riscos; psicologia.

\section{A critical to medicalization of facet for risks management}

\section{Abstract}

This paper presents a theoretical analysis of current events questioning format, including in particular the medicalization for risk management, education, city, work and family. It presents conceptual subsidies, based on philosophy, psychology, education, sociology and history. Practices of the World Health Organization on the classification of bodies and the resulting policies are part of the gear medicalization of education and society in the present, by means of risk management. One sure way to govern the life and conduct is founded by medicalized regulation of bodies today. Thus, the objective is to contribute to the discussion of this practice and the concerns about its effects, in the experiences to be today. It is possible to conclude that medicalization expands in the logic of the formation of healthy subjectivity and a supposed style of existence based on the notion of well-being and quality of life as behavioral aspects and related to the perception of risks. Thus, medicalization starts to operate by health promotion as risk management in the name of health as educational and preventive performance.

Keywords: medicalization; education; government of life; risk management; psychology.

\section{Una crítica a las facetas de la medicalización por la gestión de riesgos}

\section{Resumen}

Este artículo aborda un análisis teórico en forma de problematización de la actualidad, incluyendo, en particular, la medicalización a través de la gestión de riesgos, en la educación, en la ciudad, en el trabajo y en la familia. Por tanto, presenta subvenciones conceptuales, basadas en la filosofía, la psicología, la educación, la sociología y la historia. Las prácticas de la Organización Mundial de la Salud sobre la clasificación de órganos y las politicas resultantes forman parte del engranaje de medicalización de la educación y la sociedad, en la actualidad, a través de la gestión de riesgos. Cierta forma de gobernar la vida y el comportamiento se fundamenta en la regulación medicalizadora de los cuerpos de hoy. Así, el objetivo es contribuir a la discusión de esta práctica y sus efectos inquietantes sobre las vivencias del ser, hoy. Es posible concluir que la medicalización se expande en la lógica de la formación de una subjetividad sana y un supuesto estilo de existencia basado en la noción de bienestar y calidad de vida como aspectos conductuales y relacionados con la percepción de riesgos. Así, la medicalización comienza a operar por la promoción de la salud como gestión de riesgos en nombre de la salud como desempeño educativo y preventive.

Palabras clave: medicalización; educación; gobierno de la vida; gestión de riesgos; psicología.

\section{Introdução}

Pensar, com alguns aportes da Psicologia Social, o governo medicalizante das condutas, que aciona a gestão de risco para aumentar e modular desempenhos, passou a ser recorrente em nossa sociedade e a forjar efeitos preocupantes no plano da fabricação de subjetividades inca-

\footnotetext{
^Endereço para correspondência: Universidade Federal do Pará, Instituto de Filosofia e Ciências Humanas. Rua Augusto Corrêa, 01 - Belém, PA - Brasil. CEP 66075-110. E-mails: flaviacslemos@gmail.com, mlivianascimento@gmail. com, dolorescristinagomesgalindo@gmail.com

Os dados completos das autoras encontram-se ao final do artigo.
}

pazes, indóceis e disfuncionais. Tais figuras, resultantes de específicas gerências dos corpos, no presente, se tornaram clientes em potencial da indústria farmacêutica e da psiquiatrização de seus mínimos gestos. Estas condutas são descontínuas e operam em domínios distintos: a família, a cidade e o corpo.

Esses três domínios de governo da vida recortam, ainda, temporalidades distintas. Não apresentam conexão linear entre si, contudo, são operadores axiais para interrogar a extensão da medicalização social como biopolíti- 
ca. Tais figuras são o outro, o anormal, o desviante, contra os quais são empreendidas cruzadas educativas, escrutínio de condutas laborais e monitoramento de potências vitais.

Lidamos com três séries, a partir das quais não se traça um conjunto, porém jogos de forças, tramas, acontecimentos. Interessa-nos uma história-problema em contraponto à história dos grandes eventos com inícios e términos gloriosos, conforme enfatiza Margareth Rago (1985), ao abordar a efetividade da história para a vida. Propomos a problematização das práticas que forjam a medicalização das capacidades e funcionalidades da vida, bem como do que vem sendo denominado resiliência e disfuncionalidade a compensar, na gestão de riscos, tendo em vista as análises de Castel (1987). A família, a infância, a cidade e o trabalho entram na composição dos processos de medicalização, por meio da promoção e da gerência de performances.

O sonho de uma sociedade neoliberal é empresariar os rendimentos e desempenhos, de sorte a ampliar e modular corpos, efetivando uma educação baseada na pedagogia de competências e habilidades. Essa lógica empresarial de viver busca investir em todas as capacidades e até mesmo em reduzir déficits em prol do empreendedorismo focado na diminuição das limitações e das disfuncionalidades através de associações, cooperativas e reserva de vagas por cotas e do aumento dos desempenhos que já são altos, para fazer produzir cada vez mais os que têm resultados medianos e altos, mas que podem render mais e mais.

Tanto Foucault (2008a) quanto Castel (1987) nos ajudaram, com suas pesquisas, a pensar essas práticas e a problematizá-las. Portanto, pretendemos usar as ferramentas de ambos para interrogar a gestão de riscos e capacidades, na atualidade, pela medicalização das condutas ditas de superação de si, ou seja, de resiliência, no que se denomina processos de desenvolvimento. No texto, publicado em 1969, com o título Médicos, Juizes e Bruxos XVII, Foucault (2011, p. 284) explicita não haver domínio que pertença exclusivamente à medicina, sendo a doença, por conseguinte, "[...] em uma dada época e em uma dada sociedade, o que encontra - prática ou teoricamente - medicalizado".

Dessa maneira, a Psicologia Social pode colaborar em uma vertente interrogante dos processos em jogos na criação da medicalização dos desempenhos que fabrica incapazes, indóceis e disfuncionais em uma determinada sociedade, que os estigmatiza, governa no campo da anormalidade e encaminha pela gestão de riscos.

Como reconhece Deborah Lupton (1997), diferentemente das vertentes críticas emergentes nas décadas de 1960 e 1970, a respeito da medicalização, as quais se concentraram na figura do médico e nas práticas atinentes aos saberes da medicina, os aportes foucaultianos e de Castel se apresentaram como uma deriva que não nega a importância das primeiras, mas descentraliza o objeto sobre o qual se debruça. As pesquisas dos autores sobre medicalização abordam diversos domínios, deixando claro que a figura do médico e o saber médico são fundamentais para análise, mas que esta não deve se restringir apenas aos discursos da medicina.

Foucault e Castel se recusaram a efetuar uma história linear do saber médico cujos limites estão prefixados. É preciso examinar as condições de existência, as leis de funcionamento e as regras de transformação das práticas medicalizantes. Assim, no presente artigo, buscamos uma crítica à produção histórica das figuras dos indóceis, dos disfuncionais e dos incapazes, por meio de práticas de medicalização pela gestão de riscos.

\section{Uma crítica às artes de governo baseadas na gestão da resiliência e de risco}

Nas conferências $O$ nascimento da medicina social (1979a) e A política de saúde no século XVIII (1979b), Foucault problematiza a família medicalizada e medicalizante à qual são dirigidas encomendas para educar e se relacionar, em termos de regras de promoção da saúde. Família que vigia os seus integrantes, sendo regida pelos padrões difundidos nos manuais de saúde, higiene, desenvolvimento, alimentação e atividades físicas. Entrecruzam-se o governo das crianças e o governo das cidades, o governo da vida sexual e o governo das grandes epidemias.

Deparamo-nos com uma trama na qual ninguém está suficientemente a salvo das doenças à espreita, ninguém está isento da conclamação a compor os corpos dóceis, as quais têm como contraponto os indóceis pecados da carne infiel, as temidas doenças da degenerescência, a morte a que se chega pelas paixões. Precisa-se dos corpos dóceis, das mentes quietas, das mãos ocupadas.

As práticas de medicalização operam por múltiplas capturas. Especialistas da norma entram na família, dão orientações e conselhos. Instrui-se sobre o cuidar, que deve ser especializado com base na obediência à risca das prescrições sobre a educação. Almanaques ilustrados substituem largos manuais de condutas, visando a tornar ampliados os seus círculos de divulgação, bem como se expandem os livros para crianças com regras morais e deveres, para conservar e manter uma suposta boa saúde.

No decorrer do século XIX, quando as famílias são alçadas ao lugar de submissas e fragilizadas, especialistas passam a classificá-las como em risco e desqualificá-las não apenas como negligentes e ausentes, mas também como disfuncionais. Uma insígnia se sobrepõe a outra, numa abertura infinita - os mal-estares vagos passam a ser inscritos na precisão do recorte diagnóstico médico, psiquiátrico, pedagógico e, paradoxalmente, essa sobreposição cria vazão para que o prazer as atravesse, num jogo de dupla incitação entre este e as relações de poder.

Costa (1989) destaca como os médicos buscaram compor forças com as mulheres mães, de modo a ajudá-las a quebrar o patriarcado e, assim, interferiram em suas condutas, tanto na dimensão procriativa quanto sexual e materna. Foi pela generalização da medicina social que o Estado pôde fazer da família um operador importante das disciplinas e da governamentalidade, de acordo com Donzelot (1986). 
A medicalização da família se deu, em grande parte, pela medicalização da mulher, que deveria vigiar o esposo e os filhos, medicalizando-os. Ao mesmo tempo, o lugar de trabalho deveria ser também um espaço medicalizante dos trabalhadores, como vimos no item anterior. Dessa maneira, o controle dos corpos dos homens se faria de modo simultâneo ao de sua família nuclear. Controle e incitação de prazeres, num jogo de coibições e desejos - gozos solitários e expiação por confissão, leitura de folhetins e exaltação do cunho inofensivo do conteúdo adocicado.

Os estudos de Foucault (1979a, 1979b, 1988, 2002, 2006) auxiliam imensamente a interrogar os efeitos e a produção do poder médico sobre o corpo da mulher e sobre a infância. Ao afirmar que o poder é produtivo, favorece as análises da intervenção da medicina social e suas práticas de cerceamento da mulher, que fica reduzida à função da maternidade e formação do cidadão. Os filhos pequenos, educados cuidadosamente com vigilância e cautela, cresceriam saudáveis e subjetivados pelo empreendimento de si e dos outros, caso os pais obedecessem minuciosamente às orientações de educação em saúde, de acordo com as normas médicas (COSTA, 1989; DONZELOT, 1986).

Aos adolescentes que não se enquadram no cuidado, deseducados e rebeldes, pobres e não branqueados, resta-lhes as práticas de formação nas instituições que os guardam, enquanto os demais habitantes das cidades estão assustados e investem nos mercados de tecnologias de segurança. Nas instituições correcionais renomeadas sob os auspícios do Estatuto da Criança e do Adolescente, estes são chamados a participar e integrar o próprio processo de obediência, que inclui o de seguir estritamente o seu lugar na partição funcional das cidades.

Em uma dobra perversa, cabe aos especialistas avaliar a capacidade de resiliência dos adolescentes empobrecidos e não branqueados, capacidade esta que, em última instância, consiste em continuar resistindo, mesmo diante das adversidades. Ao chamado resiliente se exige conformidade, e a resiliência nada cobra de uma partição menos desigual, a qual faz com que reste a alguns ser dessa maneira examinados. Nesse aspecto, a utilização do conceito de sujeito resiliente abarca a visão que analisamos, qual seja a de transformar sofrimento em prazer, superar dificuldades e incapacidades e fazer dos supostos riscos oportunidades de crescimento e um empreendimento subjetivo. A resiliência é um conceito criado na física, em 1807, para se referir à resistência à pressão de materiais submetidos a determinados processos de impacto. Foi apropriado pelas ciências sociais e humanas, após a II Guerra Mundial, ganhando intenso uso na psicologia organizacional e na psicologia do desenvolvimento de base cognitivista comportamental, por volta da década de 1990, no século XX. Passou-se a usar o conceito de resiliência para explicar a capacidade humana de resistir ao sofrimento oriundo dos riscos e da vulnerabilidade enfrentados, assim como de superá-los (OLIVEIRA, 2012).

As famílias são cada vez mais avaliadas em suas competências parentais, em nome de políticas sociais compensatórias de educação e de saúde, as quais exigem para os filhos direitos a cuidados advindos dos pais, nomeados como competentes e hábeis para proteger e educar, com base em um conjunto de normas, leis morais e manuais de medicalização. Assim, por meio desse processo de vigilância e de determinação da vida certa, a família torna-se medicalizante.

Quando avaliadas, por meio de escalas aplicadas por peritos médico-psicológicos e psicopedagogos, como disfuncionais e incapazes, com baixas competências e poucas habilidades comportamentais e cognitivas, as famílias são classificadas como de risco e vulneráveis, devendo ser alvo de tecnologias sociais e psicológicas. Ou, ainda, no que se refere ao plano dos direitos, devem adquirir capacidades de governar-se e de governar seus filhos, a partir de saberes da norma. Cada desvio dessas famílias nomeadas como incapazes é computado como fator de risco. Um conjunto desses fatores as coloca em um sistema social, em uma rede de proteção destinada à expansão das habilidades de cuidado e educação esperadas pela sociedade de controle, medicalizante e neoliberal.

\section{A fabricação dos disfuncionais pela medicalização do espaço urbano: cidades purificadas e segregação social}

A organização dos espaços urbanos, surgida na França no século XIX, com vistas tanto à limpeza social das cidades quanto a tudo que impossibilitasse processos de disseminação de doenças e de sua produção, tornou-se uma prática de economia política e de gerência de riscos, na medicalização das cidades. Foucault (1979a) salienta os processos de medicalização que emergem na Inglaterra e, depois, se generalizam, voltados aos corpos dos trabalhadores e dos pobres. Nessa conferência, proferida no Rio de Janeiro, na UERJ, Foucault destaca que a saúde ganha estatuto no controle da força de produção do trabalhador. Impedir o absenteísmo dos trabalhadores, criar serviços de vigilância da saúde deles, encomendar-lhes exames de admissão e demissão, exigir-lhes avaliações de saúde periódicas, vincular sua produção e ascensão ao estilo de vida saudável e gerir riscos de acidentes e adoecimentos, durante o processo de trabalho, estão entre as práticas que emergem na esfera da medicalização dos corpos dos trabalhadores.

Nesse conjunto de análises, é possível trazer também o que Oliveira (2012) ressalta sobre resiliência, ao apontar que esse conceito tem sido utilizado na gestão de pessoas para se lidar com o nomeado stress laboral e com a oferta de instrumentos para superá-lo, a partir de receitas cognitivo-comportamentais, pelo gerenciamento de crises, pelo governo da vida e pela modulação de riscos e vulnerabilidades. Por esse operador, produz-se o trabalhador culpado frente aos processos de sofrimento. A resiliência coloca em evidência uma medicalização desenvolvimentista, materializada na gestão de risco e no recorte da vida em ciclos dos quais se espera atividade contínua. Fazer com que a maior parte do contingente populacional esteja empregada se torna uma obsessão moderna, preferencialmente em empregos formais dos quais se possam controlar os fluxos de força de trabalho e impostos, os fluxos de investimento e os resultados laborais 
e os custos da previdência, processos que se tornaram um problema com a consolidação de uma racionalidade neoliberal de governo.

Um tenso equilíbrio democrático que, arregimentando o trabalho, há que garantir a miséria que o sustenta, já que boa parte das suas instituições deriva de antigos dispositivos de filantropia. Garantir a funcionalidade da população passa por políticas de segregação espacial e partição do espaço urbano, de maneira que a miséria ou o baixo salário de alguns não afete a pureza das cidades organizadas em prol do desenvolvimento: das menores cidades, que visam a ser exemplos de planejamento, às maiores, que objetivam se aproximar cada vez mais de modelos chamados sustentáveis, característicos do empresariamento da vida.

Essas tecnologias individualizam e levam a um duplo processo de psicologização e medicalização, em nome da modulação de performances, de modo a cada vez mais ampliá-la e reduzir danos e doenças, que implicam custos em termos de economia política da saúde. No Brasil, movimentos sociais vêm assinalando a urbanização e a arquitetura voltadas a uma perspectiva de pureza e perigo.

As reformas são feitas em nome da revitalização/ reciclagem dos centros urbanos, que podemos ler como retirada forçada dos pobres e dos chamados refugos da sociedade das áreas pretendidas pela especulação imobiliária, da criação de um paisagismo turístico em prol da circulação securitária e do consumo seguro e do empreendedorismo econômico político. Apesar do investimento maciço no emprego formal e no controle do recebimento dos parcos benefícios sociais, existem aqueles que não trabalham formalmente, a exemplo dos ambulantes. Persistem, assim, aqueles que vivem à margem, nas calçadas, instituindo uma ordenação social em torno do consumo de substâncias psicoativas.

Em várias cidades brasileiras, com destaque para São Paulo, a segregação espacial conduziu à instituição informal de verdadeiras drugvilles, conhecidas como cracolândias, que hoje se configuram como figuras máximas dos disfuncionais, sendo os usuários comparados a "zumbis sociais", ora vítimas a serem internadas compulsoriamente, numa violação aos Direitos Humanos, ora potenciais criminosos que vagam depois da instauração de uma polícia que visa a impedir novas fixações no espaço das cidades.

Raquel Rolnik (2009) vem analisando criticamente essas práticas em São Paulo e em outras cidades brasileiras, ao que vem nomeando como "políticas de gentrificação", frequentemente acompanhadas de "políticas de revitalização". A ordenação das cidades como faceta da medicalização traz a perspectiva de que o acesso ao espaço deve acontecer com o mínimo de riscos e perigos, para que haja segurança na circulação de pessoas e bens, informações e consumo, viagens, passeios, trabalho, estudo, lazer e cuidados diversos.

Uma cidade dita medicalizada, ou seja, com qualidade de vida, se torna motor de empreendedorismo, portanto, de investimentos em capacidades e autossuperação, na modelação dos corpos a se tornarem resilientes e se desenvolverem em prol da capitalização de suas capacidades, competências e habilidades a serem expandidas. Tal se faz a partir dos recursos ofertados por uma cidade medicalizada. Assim, é possível analisar a oferta de oportunidades como mecanismo de segurança para lidar com a geração de renda, com a educação em saúde, para evitar e minimizar os riscos e os gastos públicos com políticas sociais, bem como a realização de políticas compensatórias para segmentos sociais assinalados como em condição de risco e/ou vulnerabilidade.

\section{Interrogando a gestão das vidas como ativas pela bonificação e o horror às incapacidades}

A denominada "vida ativa" é um conceito da Organização Mundial da Saúde (OMS, 2001). Ele define que se deve cuidar da saúde desde o nascimento, para que se possam reduzir danos e gerir riscos de doenças futuras. Evitar perdas severas e graves de capacidades do corpo, nomeadas como funcionais, é um dos principais objetivos ligados a esse conceito e à criação de programas para exercícios físicos e prevenção de possíveis psicopatologias. Recomendam-se práticas de combate ao fumo, ao sedentarismo, estimulam-se exercícios físicos, consultas a nutricionistas e clínicos gerais com frequência, e a busca recorrente e precoce de serviços preventivos de doenças crônicas.

Para a OMS (2001), a depressão é uma das doenças mais incapacitantes. Diante disso, propõe que haja prevenção e medicação da doença e avaliação da família, a fim de que se evitem prejuízos financeiros e produtivos às corporações, ao sistema de saúde pública, à sociedade de modo geral. Para os sujeitos produtivos, o argumento da OMS é que a depressão retira o talento, diminui a produção e a energia para o trabalho, dá prejuízos à família, resulta em danos para economia, reduzindo os lucros das empresas.

A garantia da saúde é atrelada às práticas que requerem sujeitos aptos ao uso do tempo: céleres, proativos, eternamente rejuvenescidos. Há uma encomenda à produção da oferta de medicamentos de conforto e à criação de demandas de "vida ativa" como necessidades. Nesse sentido, na sociedade contemporânea, remédios ganham cada vez mais destaque, para manter as relações sociais e afetivas, para a estética do corpo e os apelos da eterna juventude, para melhorar o desempenho físico e sexual, para estimular a criatividade, apenas para citar algumas das finalidades que lhes são atribuídas, sendo comercializados de modo desmesurado, gerando lucros imensos para a indústria farmacêutica.

No Brasil, recentemente, a Agência Nacional de Saúde Suplementar (ANS) criou um sistema de bonificação de riscos, em que premia trabalhadores com descontos no pagamento de planos de saúde privados empresariais, caso comprovem que fazem exercícios físicos regulares em academias, não fumam, nem bebem álcool, fazem exames regulares de saúde, têm uma alimentação considerável saudável etc. Para a ANS (BRASIL, 2011), trata-se de uma gestão de riscos de adoecimento e promoção de saúde, interferindo em uma política econômica de saúde do trabalhador. Essa Resolução incentiva a adesão de 
hábitos saudáveis e de envelhecimento com qualidade de vida pelo chamado Programa para Promoção da Saúde e Prevenção de Riscos e Doenças do Ministério da Saúde e da Agência Nacional de Saúde Suplementar.

Os trabalhadores que utilizam os planos de saúde privados podem aderir e assinar um contrato com as regras da adesão. Em troca, recebem benefícios, como descontos de $30 \%$ na mensalidade do plano de saúde e outras premiações. O objetivo dessa Resolução é prevenir o desenvolvimento de doenças crônicas, tais como câncer, diabetes e hipertensão, além de incentivar a prevenção e a promoção da saúde, nomeada como "ativa", dos trabalhadores.

Dessa maneira, é interessante pensar as práticas de medicalização, gestão de riscos e aumento de capacidades a partir do que Foucault (2008b), no curso Nascimento da biopolítica, afirmou como formação do sujeito e da sociedade empresarial. Nela, haveria uma gestão de riscos e o investimento na população na busca frenética para aumentar capacidades e funcionalidades, em nome da segurança social e da expansão do mercado.

Do mesmo modo, o trabalho de Castel (1987), quando critica a gerência de riscos para modular performances, pode nos auxiliar a interrogar a busca da vida ativa e a criação de sistemas de bonificação em planos de saúde, bem como a indução de dietas e a realização de exercícios e exames de modo permanente, como condição de seguridade, estimulando o mercado da saúde e da vida, o empreendimento de rendimentos e performances, no plano dos usos das capacidades e funcionalidades de comportamentos, competências e habilidades a governar.

\section{Psicologia Social e algumas críticas à modulação dos desempenhos pelo empresariamento das subjetividades}

Subjetividades são efeitos de processos de subjetivação que não cessam de se atualizar e inventar modos de ser, de sentir, de pensar e de agir, em um determinado tempo e em uma sociedade específica (DELEUZE, 1992). Os processos de subjetivação são compostos por vetores históricos, sociais, culturais, econômicos e políticos (GUATTARI; ROLNIK, 2006). Interessa à Psicologia Social problematizar que subjetividades são criadas na atualidade e que implicações os processos de produção nelas envolvidos geram em termos de efeitos, nesta sociedade em que vivemos.

A gestão das capacidades e performances é avaliada e modelada em prol da formação de racionalidades empreendedoras, em busca da mercantilização das cidadanias criativas e produtivas e da capitalização de cada mínima capacidade e dos desempenhos mais cotidianos. Castel (1987) afirma que, dos anos de 1970 em diante, no século XX, cada vez mais as relações humanas e a sua gestão pelas técnicas da psicologia humanista, em suas diversas tendências, se generalizaram concomitantemente ao ambientalismo cognitivista e à psicanálise do ego, na regulação das condutas pela racionalidade gerencial de uma vida feita de escolhas e consequências, em uma perspectiva do autogoverno.
Um ecletismo teórico e metodológico foi estabelecido, no entrecruzamento dessas tecnologias baseadas na dinâmica de grupo com os mecanismos da biomedicina e das biotecnologias. As psicologias foram apropriadas por muitas áreas e setores da sociedade, convidados a comparecer na modulação de subjetividades autônomas que realizam investimentos. Ensinar e auxiliar grupos e corpos rumo ao autodesenvolvimento e à realização pessoal passou a ser um lema e uma busca frenética, hoje.

Nessa ótica, a resiliência e alguns saberes da psicologia do desenvolvimento e organizacional tiveram ampla generalização social, pelo fato de ajudarem a sustentar uma educação e o trabalho constitutivo de subjetividades empreendedoras e gestoras de performances rentáveis e de risco rumo ao denominado sucesso e crescimento pela superação permanente de si. Governar-se e crescer cada vez mais, nos resultados, para chegar às metas e ir além delas se tornou um mantra da contemporaneidade.

Para tanto, lança-se mão de medicamentos, exercícios físicos, viagens, massagens, rituais religiosos de busca de prosperidade e terapias diversas, tais como exercícios orientais, psicoterapias focais, orientações profissionais, condicionamentos de comportamentos e aprendizagens focais baseadas em técnicas neuropedagógicas, programação neurolinguística, formação de grupos de autoajuda e criação de associativismos funcionando como pequenas empresas. O governo das condutas vem efetuando a medicalização, não apenas pelas biotecnologias e pela biomedicina, mas também pela via psicológica, ao capturar comportamentos, valores, afetos, crenças, atitudes, percepções e sentimentos, como investimento rentável no neoliberalismo (FOUCAULT, 2008b). Os capitais social, relacional, educativo e humano passaram a ser alvo frequente de governo de custos e benefícios, sendo regulados e intensificados ao extremo (ROSE, 1988).

Tudo que escapar e resistir a essas estratégias será alvo de processos de medicalização dos desvios dessas prescrições e regulações das condutas. Foucault (2006) ressalta que foi pelo conceito de desenvolvimento que ocorreu a ampla psiquiatrização da sociedade. A prevenção de crises, riscos e perigos ganha importância no cenário da antecipação do adoecimento. Já no curso $O s$ anormais Foucault (2002) analisou como a medicalização passou a operar pela gestão dos desvios sociais como prevenção, em defesa da sociedade.

Os dois cursos reforçam que, ao invés de governar com preferência pelo tratamento de doenças, se generaliza o governo pela promoção e prevenção, pela identificação e mapeamento de fatores de risco que estariam antecedendo a perda de capacidades e de bem-estar. Nessa nova lógica, políticas de saúde, educação e trabalho vão se organizando para potencializar ciclos de vida e gerenciar as crises em cada um desses ciclos. A medicina social ganha legitimidade cada vez maior, na medida em que se torna ferramenta de defesa social e gestora de riscos, para aumentar a seguridade individualizada e minimizar custos de adoecimentos e tratamentos. Aproveitar até mesmo o sofrimento, as deficiências e os limites, nas 
relações sociais e familiares e no corpo, para deles extrair lucro e produtividade, é um mercado expandido em nome da segurança e da denominada qualidade de vida.

Aumentar as capacidades, reduzir as incapacidades, ampliar performances é uma preocupação permanente dos que operam com a administração e com as psicopedagogias das competências e habilidades. Caminha-se para a instauração de um "mercado da saúde" na gestão da vida, que é caracterizado por terapias, receitas, gestão da vida e pela chamada competência relacional de trabalho e de educação de cada indivíduo, o qual passa a ser um potencial cliente das tecnologias de governo da saúde.

\section{Algumas considerações finais}

Já não há tempo a perder, porque todo átimo de segundo há que ser revertido em capacidades a gerir, incapacidades a temer, perigos a controlar. $\mathrm{O}$ que nos resta como estética de vida, nessas linhas que fazem da existência um "motor contínuo", cujo sentido está em mantê-lo em constante movimento?

Peter Pál Pelbart (2014) não titubeia em reconhecer na relação com o corpo uma "bioascese". Como bem lembra o autor, está-se no domínio da vida biologizada e do sobrevivencialismo, quando as encomendas de vigor, saúde e proatividade nos são dirigidas sob a forma da resiliência, sob a forma do exame de nossas atividades físicas, na forma de exercícios bonificados ou ainda numa interminável "vida ativa". De acordo com Rose (1988), nas últimas décadas do século XX e nos primeiros anos do XXI, ocorreu um intenso movimento de fomento à modulação das subjetividades, com o objetivo de regular o aprendizado em torno do gerenciamento de si e dos outros pelas tecnologias de governo da vida e dos riscos.

Cada vez mais se é subjetivado por um trabalho permanente de modulação de nossos desempenhos, por meio do incentivo à autonomia e à flexibilidade, da perspectiva empresarial de ser e de viver, da visão de capitalização dos relacionamentos e, por fim, dos usos instrumentais neoliberais dos laços sociais e comunitários como cálculos de custo e benefício nas políticas sociais.

Castel (1987) ressalta que o domínio de uma expertise gestora de performances de risco e perigo ganha notoriedade no presente, final do século XX e início do XXI. Para esse sociólogo, os perfis humanos passam a ser calculados e gerenciados pela racionalidade de aumentar capacidades e de reduzir danos, diante das incapacidades instaladas, avaliadas e nomeadas como déficits, em risco e em perigo, por meio de diagnósticos de peritos e modulação constante da nossa produção e aumento das performances que desempenhamos. Se ficamos abaixo ou se não saímos de lugar fixo, na produtividade, somos julgados como anormais, por não alcançarmos metas cada vez mais altas e por não conseguirmos ir além de nós mesmos, na extração das forças a potencializar. Compensar os déficits das comparações com aqueles que não cessam de correr atrás da autossuperação nos coloca na condição de clientes permanentes de processos de medicalização, pela égide da avaliação de incapaz, indócil e disfuncional.
Havemos de ser dóceis quando crianças e adolescentes, funcionais na juventude e na vida adulta, ativos no trabalho e na velhice, cidadãos ativos na cidade e na comunidade. As noções de gestão de riscos e de resiliência comparecem nas três figuras sobre as quais dissertamos; resiliência na perspectiva de que governar capacidades/ incapacidades em nome da promoção do desenvolvimento humano, dito sadio, como direito é cada vez mais presente.

Concluindo, a limpeza da cidade e a gestão das capacidades se tornaram ferramentas de gestão em saúde para evitar epidemias, disseminação de doenças, possibilidades frequentes de revoltas e práticas de crimes. A medicalização da cidade passou a ser vista, também, como fundamental para a expansão das capacidades dos corpos e dos grupos sociais.

Barreiras na cidade seriam limites às funcionalidades comportamentais e cognitivas de acesso às oportunidades de desenvolvimento humano e, portanto, causariam prejuízos ao empresariamento dos capitais humano, social e afetivo, além de forjarem déficits com alto custo para toda a sociedade, em termos de seguridade, no caso de acidentes, dos impactos na saúde e na educação, em aposentadorias precoces e tratamentos caros, por exemplo.

\section{Informações sobre os autores:}

\section{Flávia Cristina Silveira Lemos}

(iD) https://orcid.org/0000-0003-4951-4435

\section{(9) http://lattes.cnpq.br/8132595498104759}

Possui graduação em Psicologia/UNESP (1999). Pedagoga, especialista em Psicopedagogia Clínica e Institucional. Mestre em Psicologia e Sociedade/UNESP (2003). Doutora em História Cultural/UNESP (2007). Realizou pós-doutorado em Psicologia e Subjetividade, na UFF, sob supervisão da Profa. Dra. Maria Lívia Nascimento, em 2016. Foi bolsista FAPESP no doutorado. É professora associada III, na graduação e no Programa de Pósgraduação em Psicologia/UFPA. Foi professora colaboradora no Programa de Pós-graduação em Educação/UFPA. Integrou a Comissão de Direitos Humanos do Conselho Federal de Psicologia (2017-2019). Integrante do Fórum sobre Medicalização da Educação e da Sociedade. Foi conselheira titular no Conselho Federal de Psicologia (gestão 2011-2013). Foi coordenadora do Programa de Pós-graduação em Psicologia/UFPA (gestão 2011-2013). Foi vicecoordenadora do Programa de Pós-graduação em Psicologia/UFPA (gestão 2010-2011). É bolsista de produtividade do CNPQ-PQ-2, desde 2013. Integra o GT ANPEPP Psicologia Política. Compõe o GT Deleuze da ANPOF. Foi membro da Diretoria Nacional da ABRAPSO (2016-2017). Integrou a Diretoria Nacional da ABEP (2017-2019) e integra a nova Diretoria Nacional da ABEP (20192022). É associada à: ABRAPSO, ABPP, ABRAPEE e ABEP. Participa do Grupo Produção de subjetividade e estratégias de poder no campo da infância e juventude. Coordena o Grupo "Transversalizando". Realiza estudos sobre: modos de subjetivação contemporâneos, práticas de medicalização e judicialização da vida; psicologia, justiça e políticas públicas; recepção sócio-histórica de Michel Foucault no Brasil e filosofia da diferença; psicologia, formação, epistemologia e história; cidade, cultura e subjetividade; dispositivo clínico, saúde mental e direitos de crianças e adolescentes. Realiza estudos sobre Deleuze, Foucault e Guattari, em Esquizoanálise, Filosofia da Diferença e Arqueogenealogia. Foi assessora especial na Pró-reitoria de Extensão da UFPA, de 2018 a 2021. Coordenadora de Relações Interinstitucionais na Pró-reitoria de Extensão, desde junho de 2021. 
Maria Livia do Nascimento

iD https://orcid.org/0000-0002-6451-484X

(9) http://lattes.cnpq.br/3426340603864148

Possui graduação em Psicologia pela Universidade de Brasília (1974), mestrado em Psicologia pela Universidade de Brasília (1978) e doutorado em Psicologia (Psicologia Social) pela Pontifícia Universidade Católica de São Paulo (1990). Atualmente é professora titular da Universidade Federal Fluminense e bolsista de Produtividade em Pesquisa CNPq. Tem experiência na área de Psicologia, com ênfase em exclusão social, atuando principalmente nos seguintes temas: produção de subjetividade, infância e adolescência, psicologia e judiciário, judicialização da vida.

\section{Dolores Galindo}

(iD) https://orcid.org/0000-0003-2071-3967

(3) http://attes.cnpq.br/6781116835399339

Possui pós-doutorado (2015-2016), doutorado (2006) e mestrado (2002) em Psicologia Social pela Universidade Católica de São Paulo (PUCSP), com Doutorado Sanduíche na Universidade Autônoma de Barcelona (2004). Graduada em Psicologia pela Universidade Federal de Pernambuco (1999). Atua como professora no Programa de Pós-Graduação em Estudos de Cultura Contemporânea da Universidade Federal de Mato Grosso. Foi vice-coordenadora e posteriormente coordenadora do Programa de Pós-Graduação (mestrado e doutorado) em Estudos de Cultura Contemporânea. Na graduação, atua como docente lotada no Instituto de Educação da Universidade Federal de Mato Grosso (2013-2014). Lidera o Grupo de Pesquisa Laboratório Tecnologias, Ciências e Criação (LABTECC), desde 2010. Atua como docente nos programas de pós-graduação em Estudos de Cultura Contemporânea e em Psicologia da UFMT. Como convidada, orienta no Programa de Pós-Graduação em Psicologia e Sociedade da UNESP/Assis. Foi da Diretoria Nacional da Associação Brasileira de Psicologia Social - ABRAPSO (2016-2017), Conselheira da ULAPSI (2016-2017) e integrou a Coordenação da Red Latinoamericana de posgrados em estudos sobre a cultura - ReLaPec (2014-2016). Compõe o GT Conhecimento, Subjetividade, Práticas Sociais da ANPEPP. Foi vice-presidente da Regional Centro-Oeste da Associação Brasileira de Psicologia Social - ABRAPSO (2012-2013) e secretária (20142015). É membro associado da ESOCITE.BR - Associação Brasileira dos Estudos Sociais das Ciências e Tecnologias, da ABRAPSO - Associação Brasileira de Psicologia Social e SBPC - Sociedade Brasileira para o Progresso da Ciência. Coordenou a Comissão de Internacionalização do Fórum de Ciências Humanas, Sociais e Aplicadas. Atua como editora de Section of Athenea Digital: revista de pensamiento y investigacion social (UABEspanha) e integra o corpo de pareceristas de diversos periódicos nacionais e internacionais.

\section{Contribuição das autoras:}

As autoras colaboraram ao longo do processo, desde a elaboração até a revisão final do manuscrito. As autoras aprovaram o manuscrito final para publicação.

\section{Como citar este artigo:}

\section{ABNT}

LEMOS, Flávia Cristina Silveira; NASCIMENTO, Maria Lívia do; GALINDO, Dolores. Uma crítica às facetas da medicalização pela gestão dos riscos. Fractal: Revista de Psicologia, Niterói, v. 33, n. 3, p. 165-172, set./dez. 2021. https://doi.org/10.22409/1984-0292/ v33i3/5746

\section{APA}

Lemos, F. C. S., Nascimento, M. L., \& Galindo, D. (2021, Setembro/Dezembro). Uma crítica às facetas da medicalização pela gestão dos riscos. Fractal: Revista de Psicologia, 33(3), 165-172. doi: https://doi.org/10.22409/1984-0292/v33i3/5746

\section{Copyright:}

Copyright (C) 2021 Lemos, F. C. S., Nascimento, M. L., \& Galindo, D. Este é um artigo em acesso aberto distribuído nos termos da Licença Creative Commons Atribuição que permite o uso irrestrito, a distribuição e reprodução em qualquer meio desde que o artigo original seja devidamente citado.

Copyright (C) 2021 Lemos, F. C. S., Nascimento, M. L., \& Galindo, D. This is an Open Access article distributed under the terms of the Creative Commons Attribution License, which permits unrestricted use, distribution, and reproduction in any medium, provided the original article is properly cited.

\section{Referências}

BRASIL. Ministério da Saúde. Agência Nacional de Saúde Suplementar. Resolução Normativa 262 de $1^{\circ}$ de agosto de 2011. Atualiza o Rol de Procedimentos e Eventos em Saúde previstos na RN no 211, de 11 de janeiro de 2010. 2011. Disponível em: https://bvsms.saude.gov.br/bvs/saudelegis/ ans/2011/res0262 0108 2011. Acesso em: 12 nov. 2016.

CASTEL, Robert. A gestão de riscos: da pós-psiquiatria à póspsicanálise. Rio de Janeiro: São Francisco, 1987.

COSTA, Jurandir Freire. Ordem médica e norma familiar. Rio de Janeiro: Graal, 1989.

DELEUZE, Gilles. Conversações. Rio de Janeiro: Editora 34, 1992.

DONZELOT, Jacques. A polícia das famílias. Rio de Janeiro: Graal, 1986

FOUCAULT, Michel. O nascimento da medicina social. In: MACHADO, Roberto (Org.). Microfísica do poder. Rio de Janeiro: Graal, 1979a. p. 143-170.

FOUCAULT, Michel. A política de saúde no século XVIII. In: MACHADO, Roberto (Org.). Microfísica do poder. Rio de Janeiro: Graal. 1979b. p. 31-44.

FOUCAULT, Michel. História da Sexualidade: a vontade de saber. Rio de Janeiro: Graal, 1988. v. 1.

FOUCAULT, Michel. Os anormais. São Paulo: Martins Fontes, 2002.

FOUCAULT, Michel. O poder psiquiátrico. São Paulo: Martins Fontes, 2006.

FOUCAULT, Michel. Segurança, território e população. São Paulo: Martins Fontes, 2008a.

FOUCAULT, Michel. Nascimento da biopolitica. São Paulo: Martins Fontes, 2008b.

FOUCAULT, Michel. Médicos, Juízes e Bruxos no Século XVII. In: MOTTA, Manoel Barros da (Org.). Arte, Epistemologia, Filosofia e História da Medicina. Rio de Janeiro: Forense Universitária, 2011. Coleção Ditos \& Escritos, v. 7, p. 284-299.

GUATTARI, Félix; ROLNIK, Suely. Micropolítica: cartografias do desejo. Petrópolis, RJ: Vozes, 2006.

LUPTON, Deborah. Foucault and the medicalisation critique. In: TURNER, Bryan S.; PETERSEN, Alan R.; BUNTON, Robin. (Ed.). Foucault, health and medicine. London: Routledge, 1997. p. 94-110. 
OLIVEIRA, Salete. Política e resiliência - apaziguamentos distendidos. Ecopolítica (online), v. 4, p. 5-129, 2012. Disponível em: https://revistas.pucsp.br/index.php/ecopolitica/ issue/view/901. Acesso em: 12 out. 2018.

ORGANIZAÇÃO MUNDIAL DA SAÚDE. Envelhecimento ativo: uma política de saúde. Tradução de Suzana Gontijo. Brasília: Organização Pan-Americana da Saúde, 2001.

PELBART, Peter Pál. Vida capital: ensaios de biopolítica no contemporâneo. São Paulo: Iluminuras, 2014.

RAGO, Margareth. Do cabaré ao lar: o mito da cidade disciplinar. Rio de Janeiro: Paz \& Terra, 1985.

ROLNIK, Raquel. Democracia no fio da navalha: limites e obstáculos para a implementação de uma reforma urbana no Brasil. Revista Brasileira de Estudos Urbanos e Regionais, v. 11, n. 2, p. 31-50, 2009. https://doi.org/10.22296/23171529.2009v11n2p31

ROSE, Nikolas. Governando a alma: a formação do eu privado. In: SILVA, Tomas Tadeu da (Org.). Liberdades reguladas. Petrópolis, RJ: Vozes, 1988. p. 30-45. Disponível em: https:// www.academia.edu/5017812/Governando_a_alma_a forma $\%$ C3\%A7\%C3\%A3o_do_eu_privado_Nikolas_Rose. Acesso em: 25 ago. 2019. 